\title{
Efektifitas Puerperal Gymnastic dan Kegel Exercises \\ terhadap Involusi Uterus pada Ibu Postpartum Hari 1 - 3
}

\author{
Kholisotin, Kholifatun Naziro, Zainal Munir, Ahmad Kholid \\ Email: kholifatunnaziro90@gmail.com \\ Prodi Studi S1 Keperawatan, Fakultas Kesehatan, \\ Universitas Nurul Jadid Paiton Probolinggo, Indonesia \\ Jln. Kh. Zaini Mun'im Karanganyar Paiton Probolinggo \\ Telp/Telg : 082264472662
}

\begin{abstract}
Abstrak
Pada masa persalinan wanita banyak mengalami perubahan reproduksi, salah satunya adalah involusi uterus, jika involusi uterus terlambat kembali seperti yang semula maka akan menyebabkan subinvolusi, tekhnik puerperal gymnastic dan kegel exercises adalah tekhnik yang paling mudah digunakan dan sangat efektif. Tujuan penelitian ini untuk mengetahui efektifitas antara puerperal gymnastic dan kegel exercises terhadap involusi uterus pada ibu postpartum hari 1 - 3 di BPM Hj. Nengah Mardani Tenggarang Bondowoso. Jenis penelitian ini menggunakan metodelogi penelitian Pre Eksperimental dengan menggunakan rancangan two grouppretestposttest design, dengan sampel 30 responden. Teknik sampling dalam penelitian ini menggunakan total sampling. Analisa data menggunakan uji paired sampel t test dan $t$ test independen. Dari hasil uji t test independent menunjukan hasil tidak ada perbedaan yang signifikan antara puerperal gymnastic dan kegel exercises dalam mengatasi involusi uterus pada ibu postpartum dengan nilai $p$ 0,039 ( $p$ value $>\alpha$ 0,05) Dari kedua teknik tersebut lebih efektif kegel exercises dalam menurunkan involusi uterus dengan hasil mean perbedaan $6,7333>$ dari pada mean puerperal gymnastic 5,8000.
\end{abstract}

Kata kunci: ibu postpartum; involusi uterus; puerperal gymnastic; kegel exercises.

\begin{abstract}
During labor, women experience many reproductive changes, one of which is uterine involution. If the uterine involution is late to return to normal, it will cause subinvolution, puerperal gymnastic techniques and kegel exercises are the easiest techniques to use and are very effective. The purpose of this study was to determine the effectiveness of puerperal gymnastic and kegel exercises on uterine involution in postpartum mothers day 1-3 at BPM $\mathrm{Hj}$. Nengah Mardani Tenggarang Bondowoso. This type of research uses a pre-experimental research methodology using a two-group interpretation-posttest design, with a sample of 30 respondents. The sampling technique in this study used total sampling. Data analysis used paired sample $t$ test and independent $t$ test. The independent $t$ test results showed that there was no significant difference between puerperal gymnastic and kegel exercises in overcoming uterine involution in postpartum mothers with a $p$ value of 0.039 ( $p$ value $>\alpha 0.05$ ). Of the two techniques, Kegel exercises were more effective in reducing involution. uterus with a mean difference of $6.7333>$ than the mean puerperal gymnastic of 5.8000 .
\end{abstract}

Keywords: postpartum mothers; uterine involution; puerperal gymnastic; kegel exercises. 
Jurnal Kebidanan Harapan Ibu Pekalongan

\section{Pendahuluan}

Setelah melahirkan, rahim seorang wanita tidak secara cepat kembali seperti semula, akan tetapi mengalami proses yang lambat. Dan pada umumnya wanita yang baru saja melahirkan seringkali mengeluh tentang bentuk tubuhnya yang bertambah melar akibat membesarnya otot-otot rahim karena pembesaran sel maupun pembesaran ukurannya selama hamil (Proverawati, A. T. W.-A. 2018).

WHO memperkirakan bahwa setiap tahun sejumlah 500 orang perempuan meninggal diakibatkan oleh komplikasi kehamilan dan setelah persalinan. Penyebab terbanyak AKI (Angka Kematian Ibu) pendarahan, Eklamsi, dan Infeksi Post Partum pendarahan yang disebabkan oleh terlambatnya involusi uterus, diperkirakan $99 \%$ kematian tersebut terjadi dinegaranegara berkembang termasuk indonesia (Immawanti, I. 2019).

Negara indonesia tercatat sebagai negara tertinggi dalam pengumpulan angka kematian ibu (AKI) yang disebabkan oleh perdarahan karna terlambatnya involusi uteri, angka kematian ibu di indonesia mencapai 470 per 100 ribu kelahiran hidup (Samsinar.2018). Sedangkan provinsi jawa timur adalah termasuk provinsi yang mengalami peningkatan angka kematian ibu (AKI) yang mencapai 93,52 per 100.000 kelahiran hidup, penyebab utama angka kematian ibu dijawa timur yaitu 31\% Eklamsia, 25\%

perdarahan, infeksi $6 \%$, jantung $12 \%$ dan lain - lain 26\% (Dwi safitri, F. B. rahayuningsih. 2017).

Kabupaten

Bondowoso

mengalami penurunan AKI pada tahun 2016 dan pada tahun 2017 hingga bulan agustus mengalami peningkatan kembali, penyebab tingginya kematian ibu tersebut disebabkan komplikasi kehamilan, persalinan dan komplikasi nifas (Azizeh, U. 2018). Berdasarkan hasil studi pendahuluan yang di lakukan pada tanggal 24 Oktober sampai 30 Oktober 2019 di BPS Hj. Nengah Mardani Bondowoso hasil dari wawancara lansung kepada bidan setempat diketahui bahwa 8 dari 10 ibu melahirkan mengalami pendarahan yang diakibatkan oleh lambatnya involusi uterus".

Masa nifas atau post partum masa dimana setelah persalinan selesaisampai 6 minggu atau 42 hari. Setelah masa nifas, organ reproduksi secara perlahan akan mengalami perubahan seperti sebelum hamil. Selama masa nifasperlu mendapat perhatian lebih dikarenakan angka kematian ibu $50 \%$ - $60 \%$ terjadipada masa nifas. Dalam angka kematian ibu (AKI) penyebab banyaknya wanita meninggal dari suatu penyebab kurangnya perhatian pada wanita postpartum (Tianastia, N. 2014).

Selama masa nifas, organ reproduksi secara bertahap kembali ke keadaan sebelum kehamilan. Salah satu perubahan dalam reproduksi adalah involusi. Involusi uterus atau kontraksi uterus suatu proses di mana rahim kembali ke kondisi pra-kehamilan. Involusi uterus juga dapat dikatakan sebagai proses mengembalikan rahim ke keadaan semula atau prakehamilan. Jika involusi uterus berjalan normal, ini dapat mengurangi insiden perdarahan, terutama perdarahan post partum yang merupakan salah satu penyebab langsung kematian ibu. Ada beberapa faktor yang mempengaruhi involusi uterus, termasuk olahraga nifas, mobilitas ibu post partum dini, inisiasi 
Jurnal Kebidanan Harapan Ibu Pekalongan

menyusui dini, nutrisi, faktor psikologis dan usia dan faktor paritas. Faktor usia, pada usia di bawah 20 tahun elastisitas otot rahim tidak maksimal, sedangkan pada usia di atas 35 tahun elastisitas otot menurun. Status gizi yang baik akan dapat menghindari serangan kuman sehingga tidak ada infeksi selama masa nifas dan mempercepat involusi uterus (Setyatama, I. P., Anggraeni, I. E., \& Pamuji, S. E. B. 2019).

Apabila uterus pada ibu postpartum mengalami kegagalan maka akan menyebabkan subinvolusi, apabila sub involusi tidak tertangani akan menyebabkan perdarahan yang berkelanjutan atau postpartum haemorrhage hingga kematian, kelancaran proses involusi uterus dapat dideteksi dengan pemeriksaan lokea, konsistensi uterus, dan pengukuran tinggi fundusuteri (Sulistyoningtyas, S. 2015).

Normal TFU ibu bersalin dihari pertama atau 24 jam pertama setelah melahirkan TFU membesar sampai pusar, pada hari kedua TFU berada $1 \mathrm{~cm}$ dibawah pusar, dan pada hari ketiga TFU berada $2 \mathrm{~cm}$ dibawah pusar, dengan melatih menggunakan teknik Puerperal gymnastics TFU akan berkurang 1$2 \mathrm{~cm}$ dibawah pusar setiap harinya dan pada hari ke-9 uterus tidak dapat teraba (Andriyani, Nurlaila, \& Pranajaya, R. 2016).

Puerperal gymnastics suatu aktifitas yang dianjurkan untuk dilakukan bagi ibu pada masa nifas, puerperal gymnastics sangat dianjurkan agar dilakukan sesegera mungkin setelah melahirkan, agar otot-otot yang mengalami peregangan selama kehamilan dan persalinan dapat kembali ke kondisi normal seperti sebelumnya (Samsinar. 2018).
Berdasarkan hasil penelitian (ramin \& ayuning, 2017) yang telah dilakukan tentang hubungan Puerperal gymnastics terhadap involusi uterus pada ibu nifas didapatkan $74,6 \%$ orang ibu yang mengalami penurunan involusi uteri dengan cepat. Sedangkan hasil penelitian (Indriyastuti, H. I., \& Kusumastuti, T. 2015). bahwa Puerperal gymnastics memang suatu treatment yang berpengaruh positif dalam mempercepat involusi uterus ibu postpartum.

Kegel exercises suatu senam otot dasar panggul Pubococeygeus yang semula dipergunakan untuk terapi pada perempuan yang tidak mampu mengontrol keluarnya urin terutama setelah melahirkan. Kegel exercises bertujuan untuk melatih otot - otot dasar panggul, otot-otot vagina, perut dan rahim pada saat persalinan pervagina melangi peregangan dan kerusakan (Pertiwi, L. B. 2019). Kegel exercises turut berperan dalam pencapaian penurunan angka kematian pada ibu dan bayi di Indonesia yang saat ini masih merupakan masalah yang besar dan harus mendapatkan perhatian khusus dari pemerintah (Sarwinarti. (2018).

Berdasarkan hasil penelitian menyatakan mayoritas responden yang diberikan Kegel exercises mengalami proses involusi uterus yang baik (89\%), sedangkan yang tidak diberikan Kegel exercises mengalami involusi yang buruk (71\%) serta terdapat pengaruh Kegel exercises terhadap involusi uterus pada ibu post partum (Samsinar. (2018). Berdasarkan hasil penelitian, bahwa terdapat perbedaan rata-rata penurunan tinggi fundus uteri, dari penelitian tersebut TFU dapat menurun hingga 2,31 cm setiap harinya (Ulfa, M. (2015). 
Jurnal Kebidanan Harapan Ibu Pekalongan

Berdasarkan fenomena di atas peneliti tertarik untuk melakukan penelitian tentang "Efektifitas puerperal gymnastics dan kegel exercises terhadap involusi uterus pada ibu post partum pada hari 1-3 di BPS Hj. Nengah Mardani.

\section{Metode Penelitian}

Desain penelitian ini menggunakan metode kuantitatif Rancangan yang digunakan dalam penelitian ini adalah rancangan penelitian Pre-Eksperiment dengan menggunakan rancangan pra-

\section{Hasil dan Pembahasan}

a. Analisis Univariat

1) Data penurunan TFU pada ibu postpartum pada kelompok intervensi (puerperal gymnastic) pascates two -group pra-post test design, yaitu melibatkan dua kelompok subjek. Kelompok subjuk pertama dan kelompok subjek pertama dan kelompok subjek kedua dilakukan intervensi ( Nursalam, 2017). Dalam penelitian ini sampling yang digunakan adalah total sampling dengan jumlah responden 30 orang. Teknik analisis data menggunakan uji $\mathrm{T}$ berpasangan (uji paried t-test) dan uji $\mathrm{T}$ tidak berpasangan (independent T-test) (Indra, 2019)

Tabel 1

\begin{tabular}{cccccc}
\hline \multirow{2}{*}{ No } & TFU & \multicolumn{2}{c}{ Sebelum Intervensi } & \multicolumn{2}{c}{ Sesudah Intervensi } \\
\cline { 3 - 6 } & $\mathbf{F}$ & $\mathbf{\%}$ & $\mathbf{F}$ & $\mathbf{\%}$ \\
\hline 1 & 1 & - & - & - & - \\
2 & 2 & - & - & - & - \\
3 & 3 & 4 & 26,7 & - & - \\
4 & 4 & 11 & 73,3 & - & - \\
5 & 5 & - & - & 3 & 20,0 \\
6 & 6 & - & - & 12 & 80,0 \\
7 & 7 & - & - & - & - \\
8 & 8 & - & - & - & - \\
9 & 9 & - & - & - & - \\
& Total & 15 & 100 & 15 & 100 \\
\hline
\end{tabular}

Sebelum dan sesudah dilakukan Puerperal gymnastic, berdasarkan Tabel .1 Hasil sebelum dilakukan puerperal gymnastic 11 responden (73,3\%) mengalami penurunan TFU pada kode $4(4 \mathrm{~cm}-5 \mathrm{~cm})$ dibawah pusar setelah dilakukan puerperal gymnastic 12 responden $\quad(80,0 \%)$ mengalami penurunan pada kode $6(6 \mathrm{~cm}-7 \mathrm{~cm})$ dibawah pusar.

2) Data penurunan TFU pada ibu postpart pada kelompok intervensi (kegel exercises) 
Jurnal Kebidanan Harapan Ibu Pekalongan

Tabel 2

\begin{tabular}{|c|c|c|c|c|c|}
\hline \multirow[t]{2}{*}{ No } & \multirow[t]{2}{*}{ TFU } & \multicolumn{2}{|c|}{ Sebelum Intervensi } & \multicolumn{2}{|c|}{ Sesudah Intervens } \\
\hline & & $\mathbf{F}$ & $\%$ & $\mathbf{F}$ & $\%$ \\
\hline 1 & 1 & - & - & - & - \\
\hline 2 & 2 & - & - & - & - \\
\hline 3 & 3 & - & - & - & - \\
\hline 4 & 4 & 2 & 13,3 & - & - \\
\hline 5 & 5 & 13 & 86,7 & - & - \\
\hline 6 & 6 & - & - & 4 & 26,7 \\
\hline 7 & 7 & - & - & 11 & 73,3 \\
\hline 8 & 8 & - & - & - & - \\
\hline 9 & 9 & - & - & - & - \\
\hline & Total & 15 & 100 & 15 & 100 \\
\hline
\end{tabular}

Sebelum dan sesudah dilakukan kegel exercises, berdasarkan tabel 5.11 Hasil sebelum dilakukan kegel exercises 13 responden $\quad(86,7 \%)$ mengalami penurunan TFU pada kode $5(5 \mathrm{~cm}-6 \mathrm{~cm})$ dibawah pusar setelah dilakukan puerperal gymnastic 11 responden $(73,3 \%) \quad$ mengalami penurunan pada kode 7 ( $7 \mathrm{~cm}-8 \mathrm{~cm})$ dibawah pusar .

b. Analisa Bivariat Perbandingan penurunan TFU pada kelompok intervensi (puerperal gymnastic dan kegel exercise.

Tabel 3

\begin{tabular}{lcccc}
\hline $\begin{array}{c}\text { Kelompok } \\
\text { Perlakuan }\end{array}$ & $\begin{array}{c}\text { Mean } \\
\text { Difference }\end{array}$ & Std. Deviation & SE & $\boldsymbol{P}$ \\
\hline Puerperal & 5,8000 & .45774 & 10,690 & \\
$\begin{array}{l}\text { gymnastic } \\
\text { Kegel exercises }\end{array}$ & 6,7333 & .35187 & 11,819 & \\
\hline
\end{tabular}

Pada Tabel 3 hasil analisa pada post test diperoleh nilai rerata puerperal gymnastic adalah 5,8000 dan rerata kegel exercises adalah 6,7333 dengan nilai $p$ value 0,039 ( $p$ value $>$ $0,05)$ dapat disimpulkan tidak terdapat perbedaan efektifitas secara signifikan sesudah dilakukan puerperal gymnastic dan kegel exercises terhadap involusi uterus pada ibu postpartum hari 1-3. Dan dengan demikian dari kedua teknik tersebut lebih efektif terhadap involusi uterus pada ibu postpartum adalah kegel exercises.

\begin{abstract}
Pembahasan
Involusi uterus juga dapat dikatakan sebagai proses mengembalikan rahim ke keadaan semula atau pra-kehamilan. Jika involusi uterus berjalan normal, ini dapat mengurangi insiden perdarahan, terutama perdarahan post partum yang merupakan salah satu penyebab langsung kematian ibu (Setyatama, I. P., Anggraeni, I. E., \& Pamuji, S. E. B. 2019).

Puerperal gymnastics suatu aktifitas yang dianjurkan untuk dilakukan bagi ibu pada masa nifas, puerperal gymnastics sangat dianjurkan agar dilakukan sesegera mungkin setelah melahirkan, agar
\end{abstract}


Jurnal Kebidanan Harapan Ibu Pekalongan

otot-otot yang mengalami peregangan selama kehamilan dan persalinan dapat kembali ke kondisi normal seperti sebelumnya (Samsinar. 2018) Dengan melakukan puerperal gymnastic dapat merangsang kontraksi uterus lebih baik sehingga menghindarkan resiko terjadinya perdarahan senam nifas diantaranya varises, thrombosis vena karena sumbatan vena oleh bekuan darah yang tidak lancer akibat ibu terlalu membatasi gerakan selama masa nifas, infeksi karena involusi uterus yang tidak baik sehingga sisa darah tidak dapat dikeluarkan, serta perdarahan yang abnormal (Samsinar. 2018).

Berdasarkan hasil penelitian (Indriyastuti, H. I., \& Kusumastuti, T. (2018). dan pembahasan yang telah dipaparkan, dapat disimpulkan sebagai berikut:

1. Kecepatan involusiuterus pada ibu nifas yang melakukan senam nifas di BPS Sri Jumiati Kecamatan Buluspesantren Kabupaten Kebumen mayoritas berada pada kategori cepat sebanyak 16 orang (76,19\%).

2. Kecepatan involusiuterus pada ibu nifas yang tidak melakukan senam nifas di BPS Sri Jumiati Kecamatan Buluspesantren Kabupaten Kebumen mayoritas berada pada kategori tepat sebanyak 16 orang (76,19\%).

Kegel exercises merupakan suatu latihan otot dasar panggul pubococcygeus. Senam Kegel ini dilakukan untuk melatih otot-otot dasar panggul, otot-otot vagina, perut dan rahim pada saat persalinan pervaginam mengalami peregangan dan kerusakan yang dapat menyebabkan nyeri setelah melahirkan. Menurut penelitian responden pada kelompok yang diakukan senam kegel, dari 9 responden yang dilakukan senam terdapat 8 responden dengan proses involusio yang baik dan 1 responden dengan proses involusio yang buruk. Dari analisis hasil penelitian tersebut dapat disimpulkan bahwa senam kegel sangat efektif untuk mempercepat proses involusio uterus (Sarwinarti. (2018).

Disamping itu, dengan latihan abdomen akan memberikan stimulus secaralurus menuju otot uterus sehingga akan membantu otot uterus berkontraksi maksimal, dengan kontraksi tersebut akan menjepit pembuluh darah yang terbuka dan menyebabkan proses involusio uterimenjadi cepat. Uterus yang berkontraksi dengan baik secara bertahap akan berkurang ukurannya, sampai tidak dapat dipalpasi di atas simphisis pubis. Berdasarkan penelitian (Ulfa, M. (2017). Terdapat perbedaan penurunan tinggi fundus uteri antara kelompok yang dilakukan senam Kegel exercises $(p=0,000<$ 0,05). Hal ini sejalan dengan pendapat ( Myles. 2009 dan Moore, Keith, et al. 2002), bahwa otot perut dan otot dasar panggul merupakan otot penyokong uterus.

Hasil analisa pada post test diperoleh nilai rerata puerperal gymnastic adalah 5,80 dan rerata relaksasi teknik benson adalah 6,73 dengan nilai $\mathrm{p}$ value 0,000 (p value $<0,05)$ dapat disimpulkan terdapat perbedaan efektifitas secara signifikan sesudah dilakukan puerperal gymnastic dan kegel exercises terhadap involusi uterus pada ibu postpartum hari 1-3. Dan dengan demikian dari kedua teknik tersebut lebih efektif terhadap involusi uterus pada ibu postpartum 
Jurnal Kebidanan Harapan Ibu Pekalongan

adalah kegel exercises.

Hasil penelitian yang dilakukan di BPM Hj. Nengah Mardani Tenggarang Bondowoso, diketahui bahwa kelompok kegel exercises memiliki nilai rata-rata lebih tinggi dari pada kelompok puerperal gymnastic. Sehingga dapat diartikan bahwa kegel exercises lebih efektif dari pada puerperal gymnastic.

\section{Kesimpulan}

Adanya pengaruh yang signifikan sebelum dan sesudah diberikan intervensi. Perbandingan antara ketiga kelompok ini menunjukkan bahwa puerperal gymnastic dan kegel exercises, lebih efektif kegel exercises untuk menurunkan TFU pada ibu postpartum di BPM $\mathrm{Hj}$. Nengah Mardani Tenggrang Bondowoso

\section{Daftar pustaka}

[1] T. Astuti and M. Bangsawan, "Aplikasi Relaksasi Nafas dalam terhadap Nyeri dan Lamanya Persalinan Kala I Ibu Bersalin di Rumah Bersalin Kota Bandar Lampung," $J$. Ilm. Keperawatan Sai Betik, vol. 15, no. 1, p. 59, 2019.

[2] A. T. Proverawati and -A W, Senam Kesehatan (Kedua). Yogyakarta, 2018.

[3] I. Immawanti, "Pengaruh Pijat Oksitosin Terhadap Involusio Uterus Pada Ibu Post Partum Di Puskesmas Totoli Majene," J. Heal. Educ. Lit., vol. 1, no. 2, pp. 113-119, 2019.

[4] Samsinar, Jurnal Fenomena. Kesehatan., vol. 1, no. 1, pp. 37-37, 2018.

[5] D. Safitri and R. F. B, "Efektifitas metode time token dalam pendidikan kesehatan tentang mobilisasi masa nifas di puskesmas Bendo Magetan,” pp. 53-67, 2017.

[6] U. Azizeh, Asuhan Kebidanan Komprehehensif (continuity of care) pada Ny " $D$ " di BPM bidan " $A$." 2018.

[7] N. Tianastia, Pengaruh Senam Nifas terhadap Penurunan Tinggi Fundus Uteri pada Ibu Post Partum di RSUP DR. R. djamil padang. 2014.

[8] I. P. Setyatama, I. E. Anggraeni, and S. E. B. Pamuji, "Pengaruh Inisiasi Menyusu Dini Terhadap Kontraksi Uterus Pada Ibu Nifas Di Puskesmas Slawi Kabupaten Tegal," J. SMART Kebidanan, vol. 6, no. 1, p. 31, 2019.

[9] S. Sulistyoningtyas, "Studi Hubungan Antara Senam Nifas, Inisiasi Menyusu Dini (IMD) Dan Paritas Dengan Involusio Uteri (Imd)," 2015.

[10] N. Andriyani and R. Pranajaya, "Pengaruh Senam Nifas Terhadap Kecepatan Penurunan Tinggi Fundus Uteri (TFU) Pada primipara Post Partum," J. Kebidanan Dan Keperawatan, vol. 9, no. 2, pp. 138-146, 2016.

[11] G. T. Utami, "Perbandingan Efektivitas Senam Nifas Dan Pijat Oksitosin Terhadap Involusi Uteri Pada Ibu Post Partum," Jom, vol. 2, no. 2, 2015. 
Jurnal Kebidanan Harapan Ibu Pekalongan

[12] S. Ramin and D. P. Ayuning, "Hubungan Senam Nifas dengan Penurunan Involusi Uteri pada Ibu Post Partum Hari Ke 1-3 di RSIA CICIK Padang Tahun 2016," Jik - J. Ilmu Kesehat., vol. 1, no. 1, pp. 117-122, 2017.

[13] L. B. Pertiwi, "Tingkat Pengetahuan Ibu Post Partum Tentang Senam Kegel Di Kelurahan Tegal Besar Kecamatan Kaliwates Kabupaten Jember Tahun 2017," vol. 1, no. 1, pp. 2017 2020, 2019.
[14] Sarwinarti, "Pengaruh senam kegel terhadap proses involusio uterus pada ibu post partum The effect of kegel exercises to the process of uterus involution i post post partum mothers," vol. 14, no. 2, pp. 145-150, 2018.

[15] Nursalam, Metodologi penelitian ilmu keperawatan, 4th ed. Jakarta Selatan: Peni Puji Lestari, 2017. 